\title{
Appendix 2
}

\section{Noblewomen in the \\ Rotuli de Dominabus}

Place names have been put into their modern form where they are identifiable. Personal names have likewise been modernised. Square brackets indicate that the information has been derived from sources other than the Rotuli de Dominabus, and an asterisk indicates that the information is entered under another individual's name, usually that of the heir. $w$ wife of, $m$. married, libr. librates, KF knight's fee, $D$ dower, $M P$ marriage portion (maritagium), $I$ inheritance, $T$ tenant, $\mathrm{TiC}$ tenant-in-chief. Lower-case abbreviations of the same indicate that although the land is not listed as dower, etc., it is likely to have been land held by that tenure, which can be deduced from the Rotuli de Dominabus or other sources. 


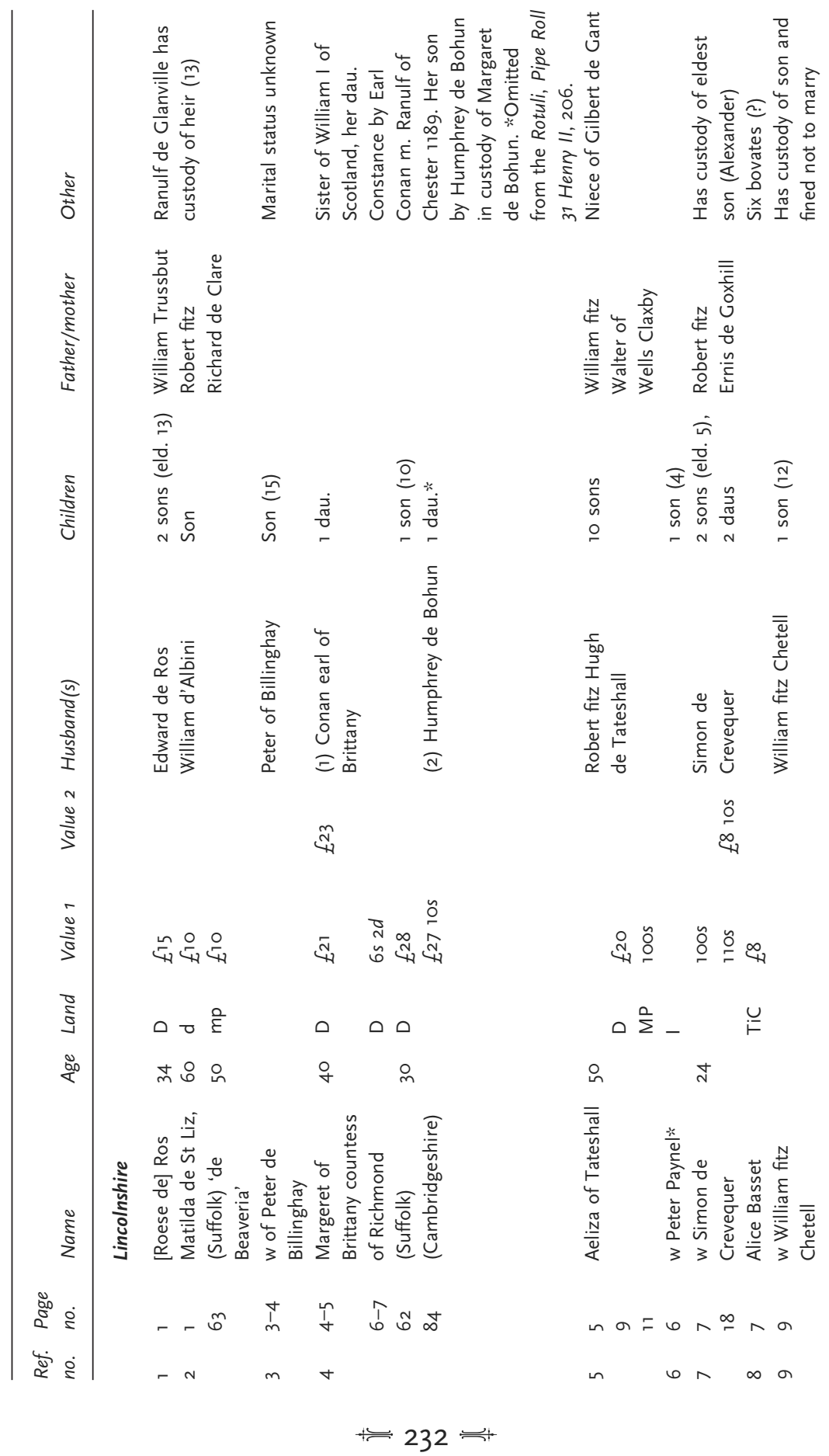




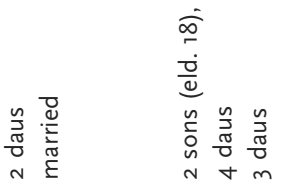

$\widehat{\dot{\varepsilon}}$

宛

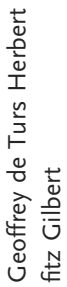

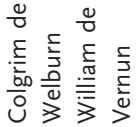



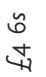

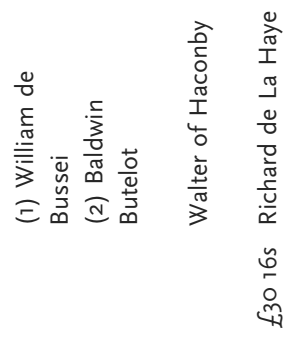

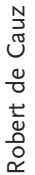

ڤั

$\stackrel{\sim}{\dddot{m}}$

$\stackrel{4}{4}$

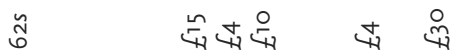

$\stackrel{4}{2}$

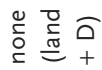

$-\stackrel{a}{\Sigma}$

음

웅요

o in

$\stackrel{+}{\circ}$

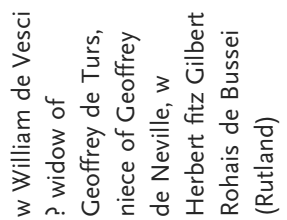

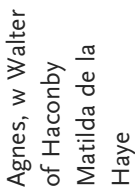

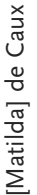

$\therefore \circ$

レ ษ

$\stackrel{2}{2}$

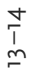

$\therefore=$

$\simeq$

$m \quad$ t

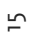




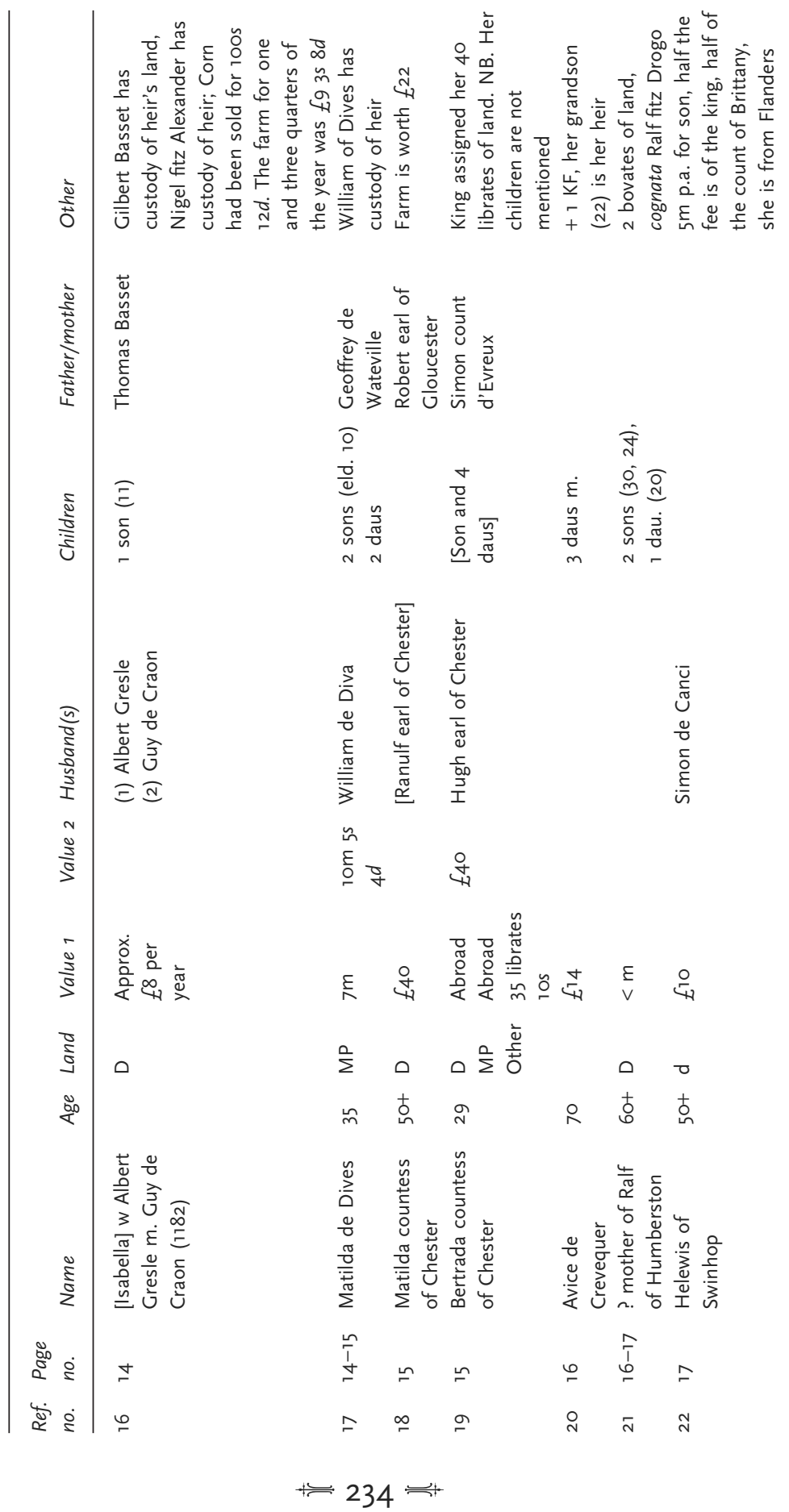




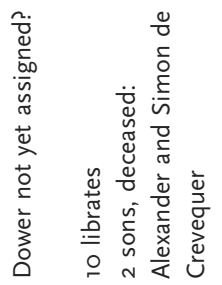

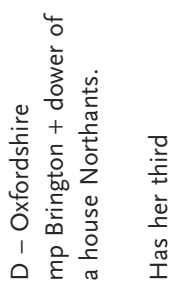

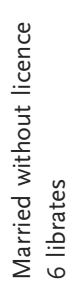
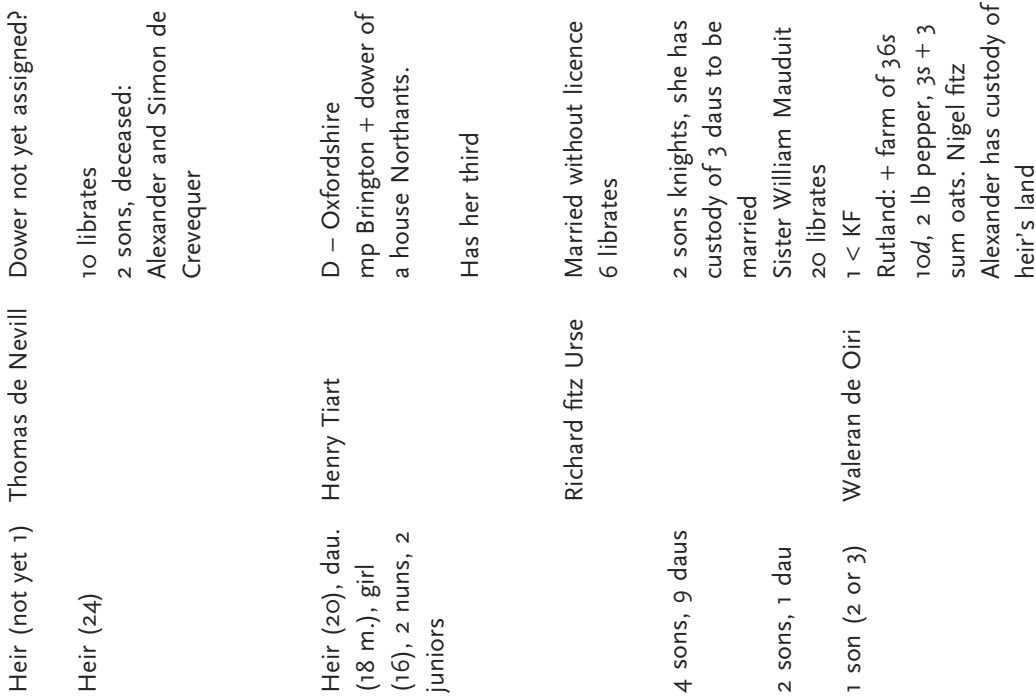

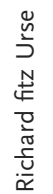

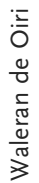

宅范

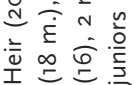
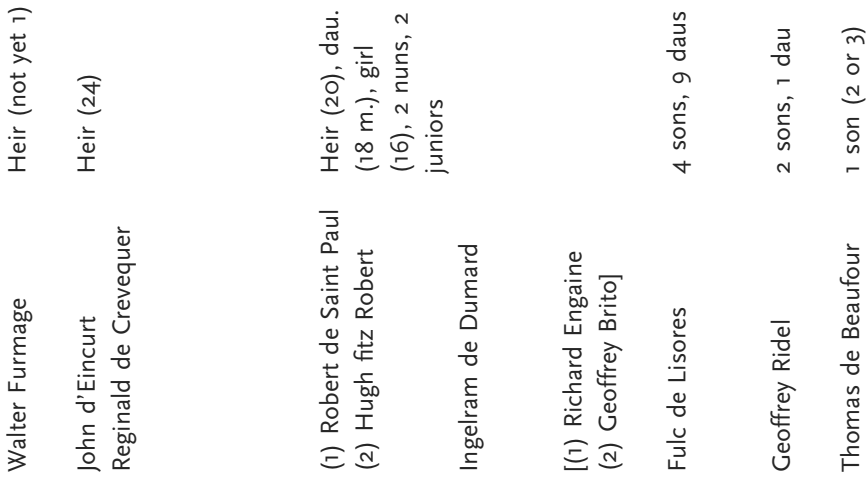

$\overline{\overline{\bar{E}}}$
$+\underset{N}{\mathrm{~m}}$

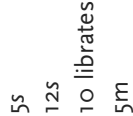<smiles>[CH]</smiles>

4

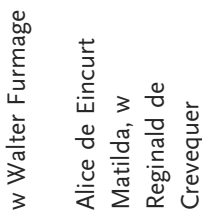

$\stackrel{2}{\sim}$

ก

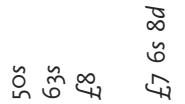

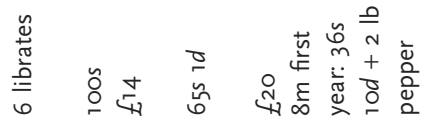<smiles>C1CCCCC1</smiles>

- 0 0 0

아

t)

융ํํ유 음

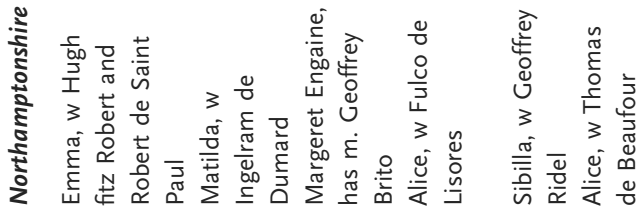

$\stackrel{\text { กิ }}{\text { กิ }}$

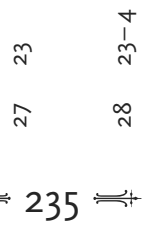

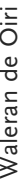

高




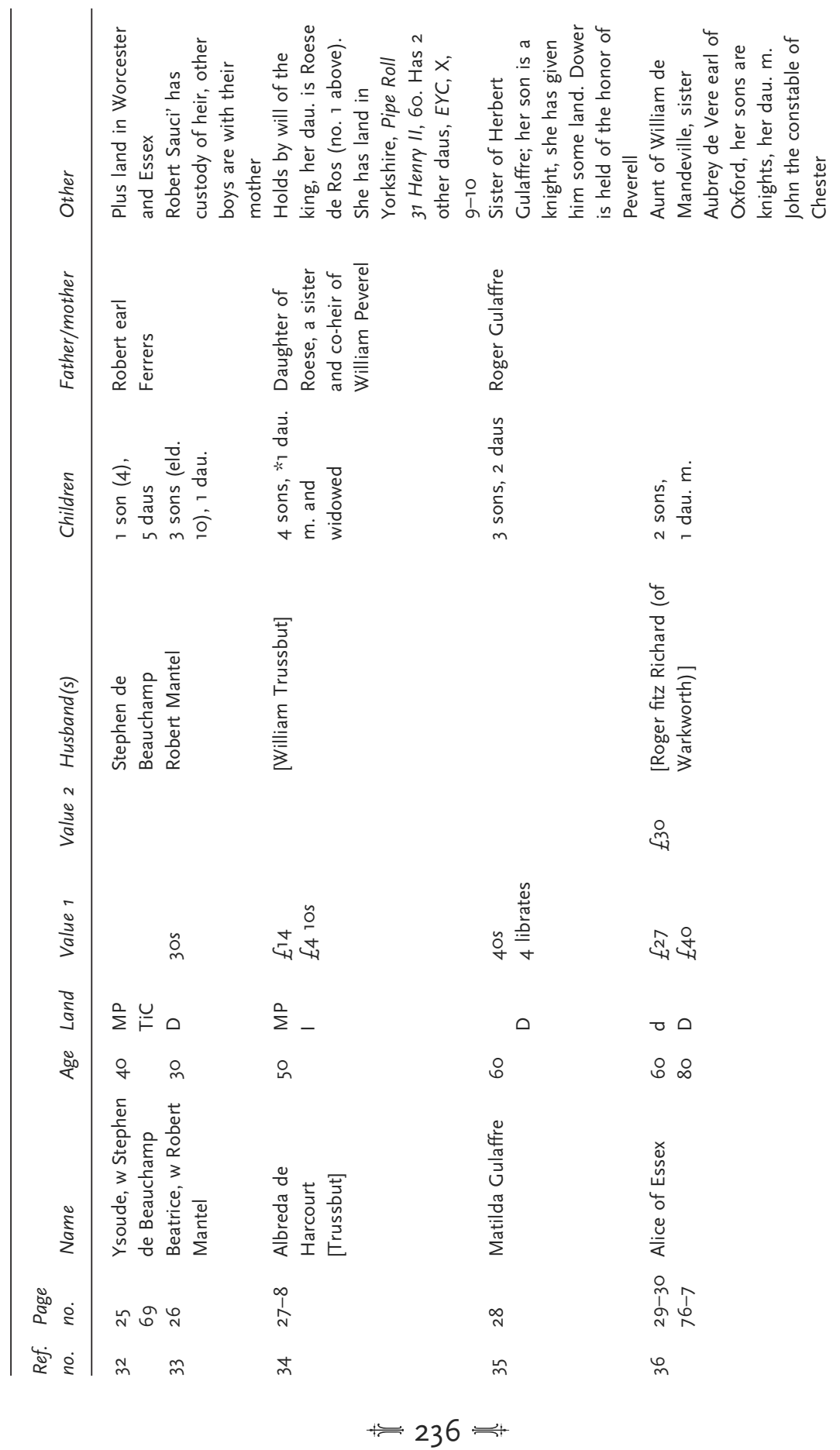



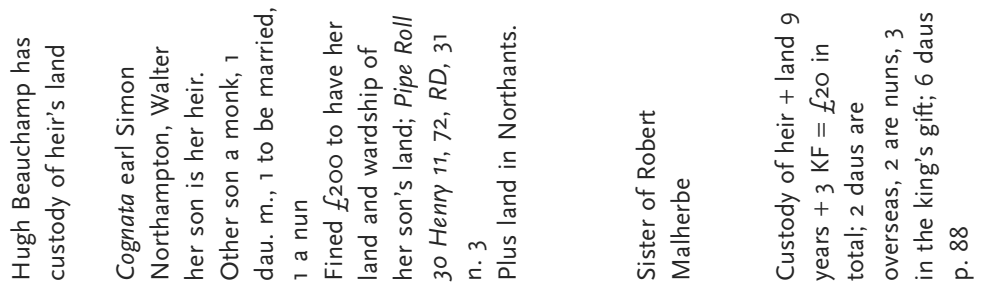

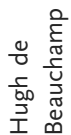

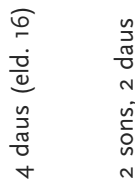
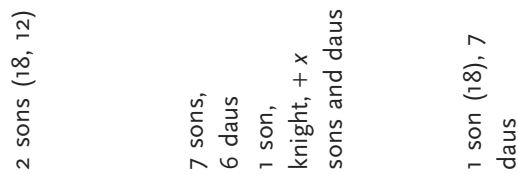

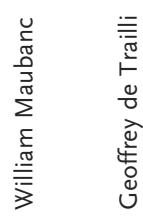

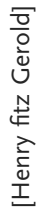

$\frac{1}{3}$
$\frac{3}{0}$
0
0
$\frac{0}{0}$
$\frac{0}{0}$
$\frac{0}{x}$

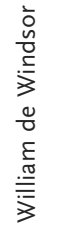

$\stackrel{N}{4}$

to

$\stackrel{n}{=}$

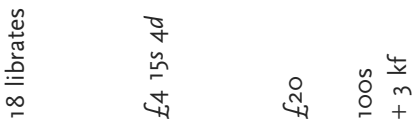

일

4
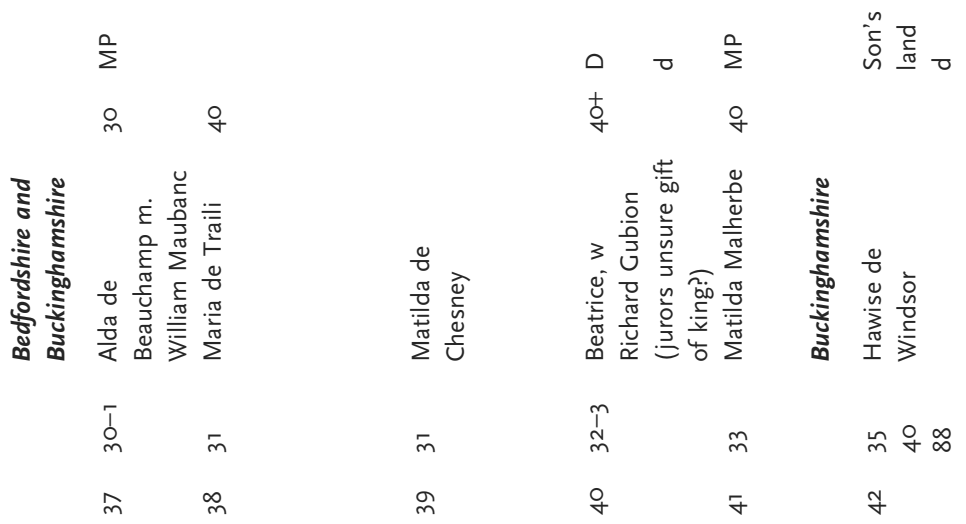

$\stackrel{n}{m}+\infty$

m

우

$m$

ร 


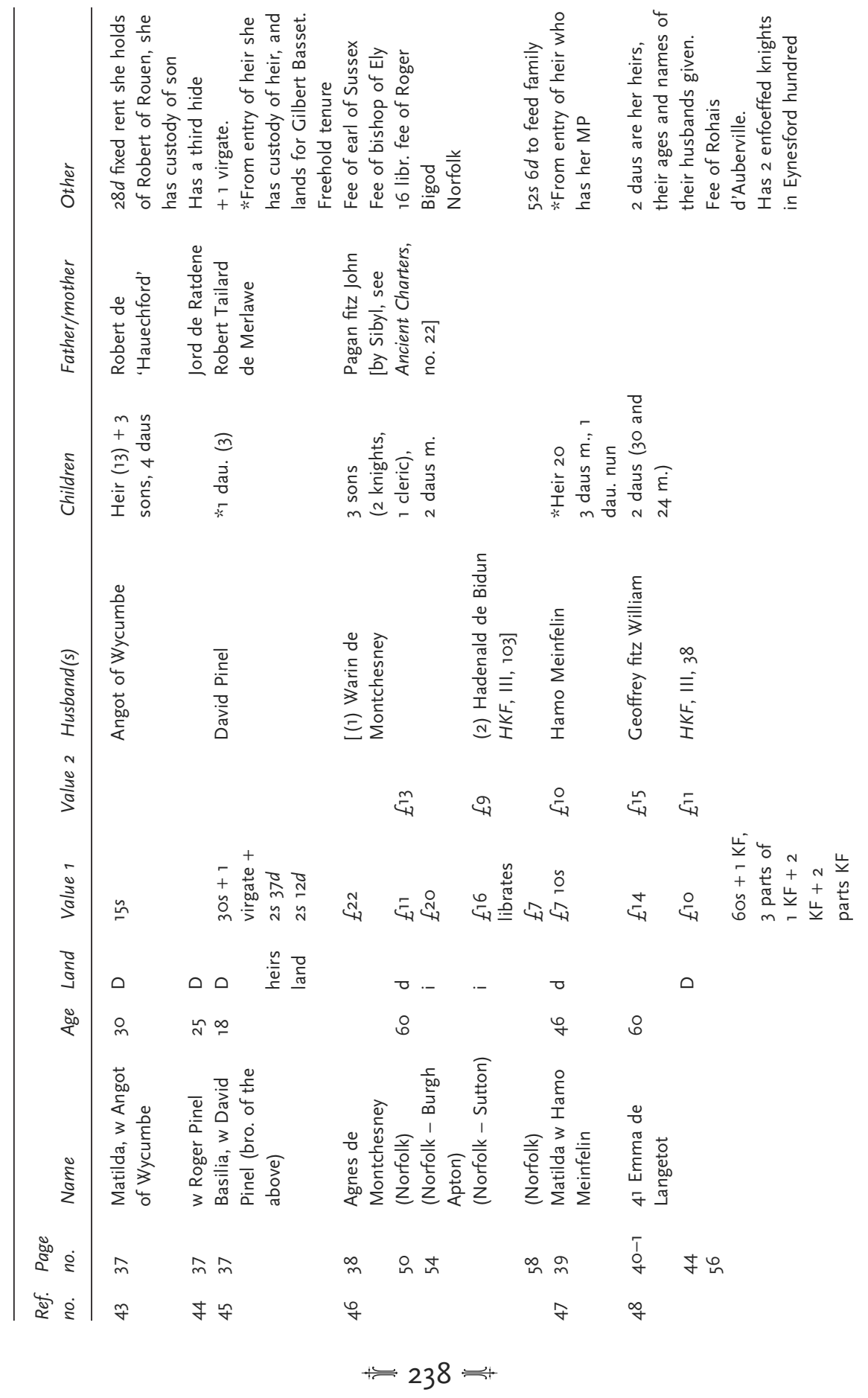




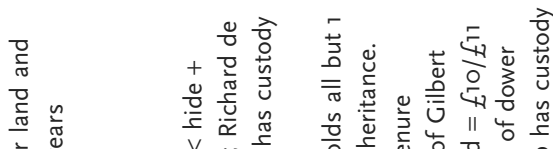

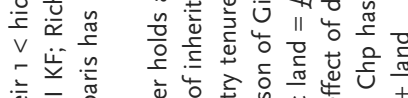

织

๘

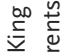

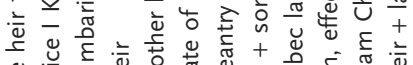

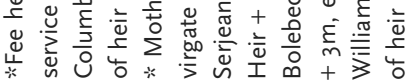

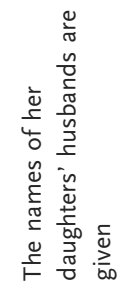

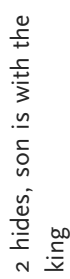

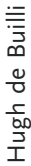

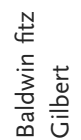

$\stackrel{0}{5}$
$\frac{7}{0}$
$\frac{0}{0}$
$\frac{0}{0}$
$\frac{5}{5}$
으

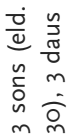

$\frac{0}{c}$
$\dot{\sigma}$
$\frac{\pi}{*}$

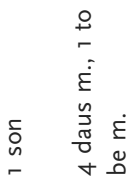

ลู
¿
$i$

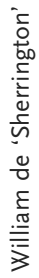

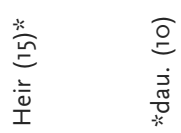

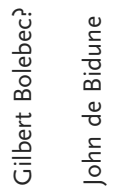

$\stackrel{\circ}{\stackrel{4}{4}}$

ณั

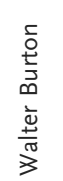

$$
\begin{aligned}
& \stackrel{0}{2} \\
& \stackrel{0}{0} \\
& \frac{0}{0} \\
& \frac{0}{0} \\
& \frac{5}{5} \\
& \text { 응 }
\end{aligned}
$$

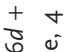

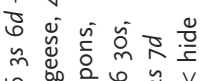

出

$\infty$

\section{$\frac{2}{\frac{5}{2}} \frac{4}{n}$}

*

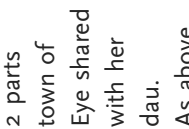

$\infty$

8

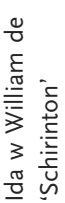

พั

คุ

ษ

$\stackrel{\circ}{1}$

○

है

$\stackrel{n}{\frac{0}{0}}$

ัั

용ำ

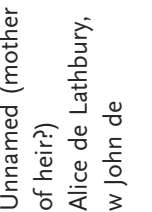

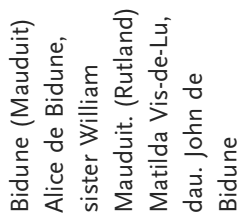

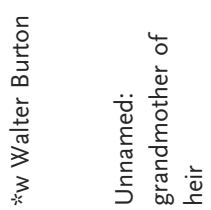

ๆ $\stackrel{ท}{\text { ก }}$

$\stackrel{+}{\stackrel{+}{m}}$

กิ เัก

นกำ 


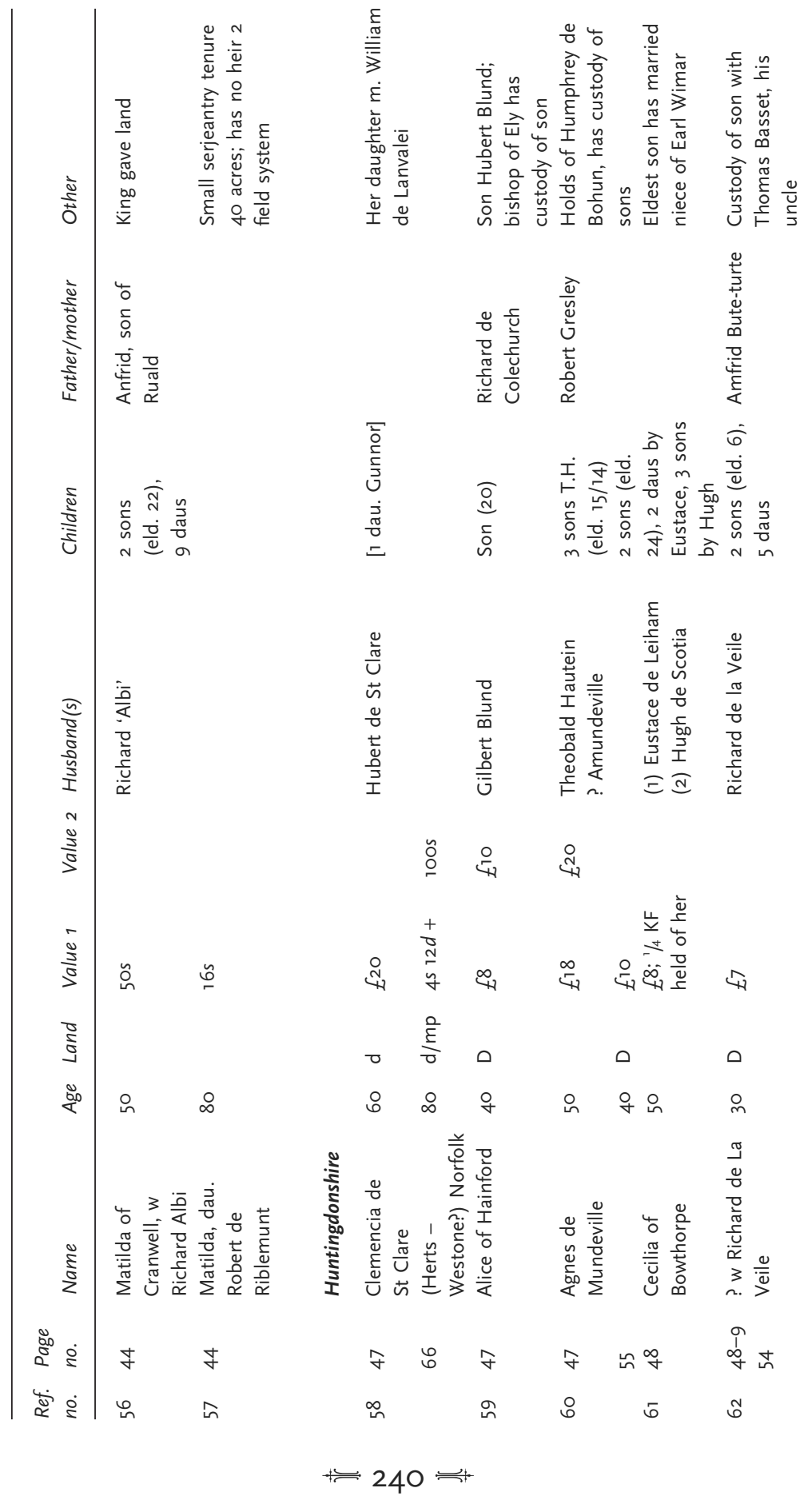




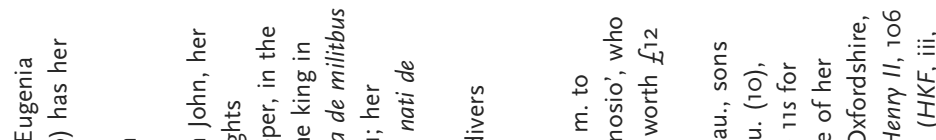

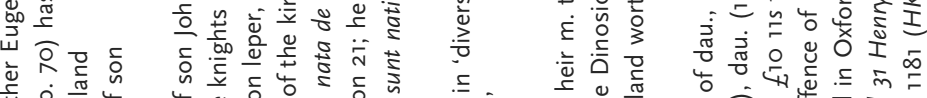

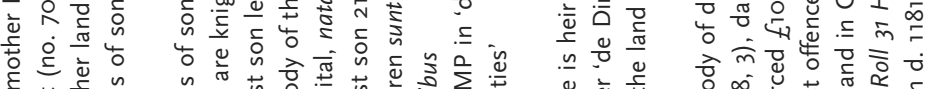

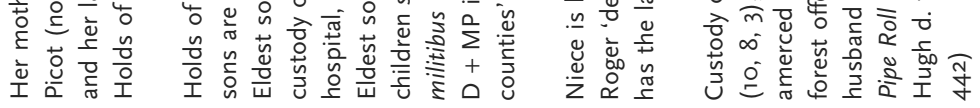

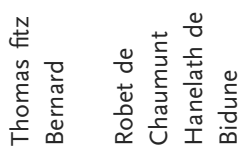

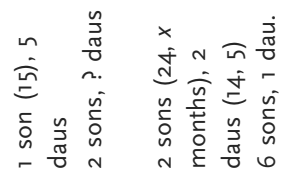

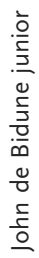

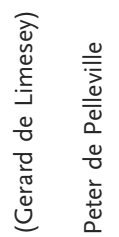

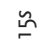
$\stackrel{N}{\stackrel{1}{\infty} \infty}$ $\underbrace{\infty}_{4}$

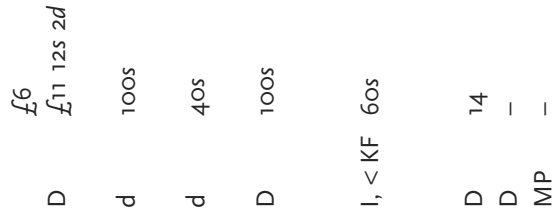

$\circ \quad \circ \quad \circ \quad q \quad \circ \quad q$

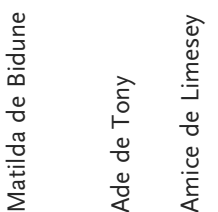

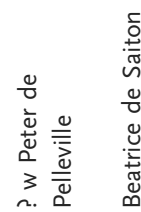

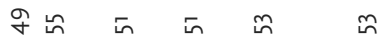
m

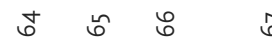

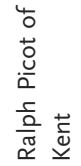

它

$m \dot{\varepsilon}$

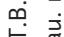

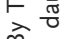

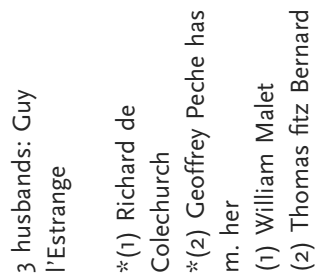

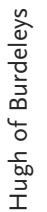

$\stackrel{\underline{0}}{\stackrel{0}{a}}$

t)

$\cong \bar{\Xi}$

E药葆

$\stackrel{\circ}{\circ}$

$\infty$

$\stackrel{4}{4}$

ㅇ

요

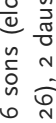

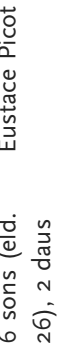

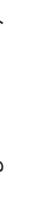

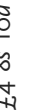

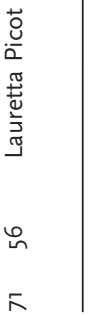




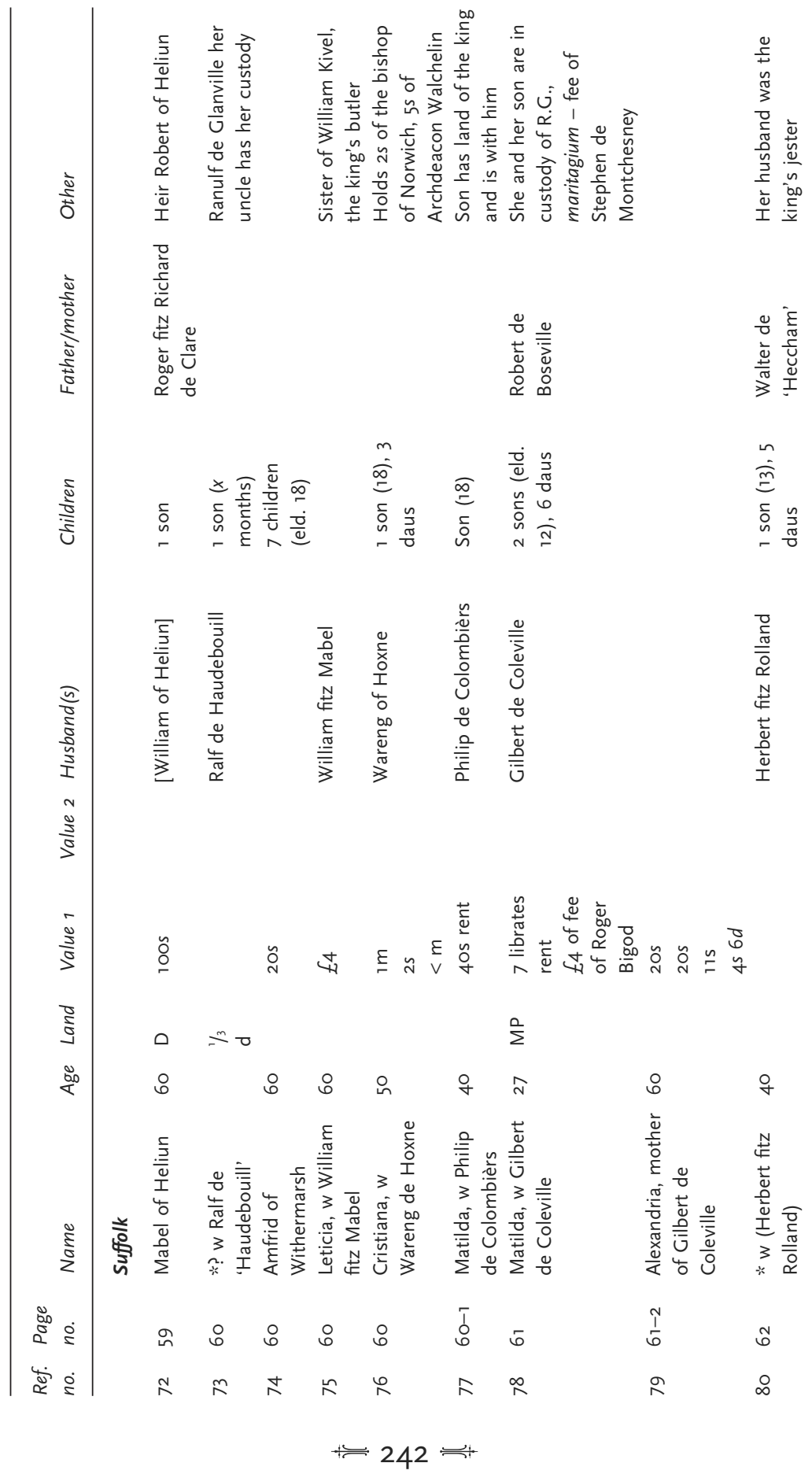




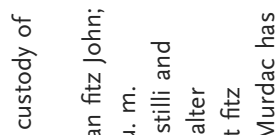

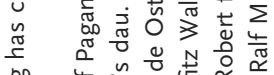

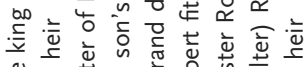

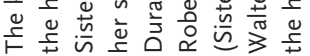

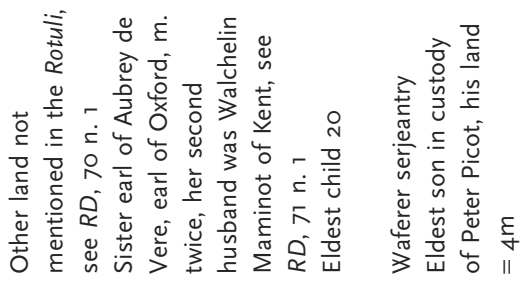

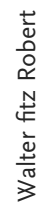

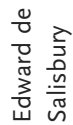

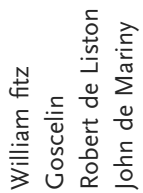

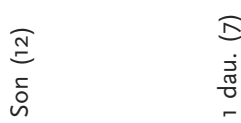

$n$
$\frac{n}{\pi}$
$\frac{\pi}{0}$
$n$
5
0
0
$n$

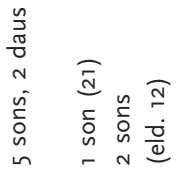

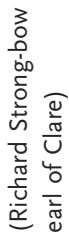

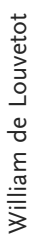

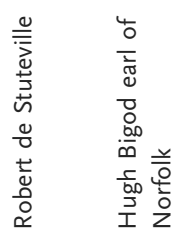

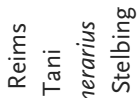

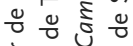

离

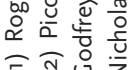

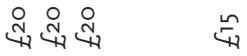

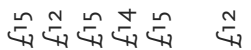

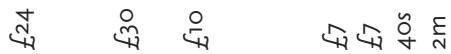

๑ 0 o. .

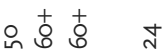

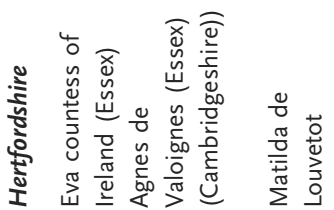

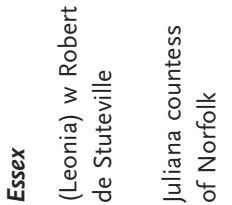

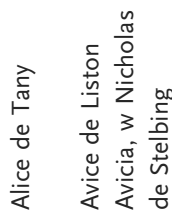

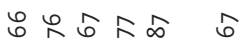

官

$\sin \frac{1}{2}$

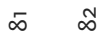

œ

Ð $\stackrel{\infty}{\mathbb{N}}$

$\infty \quad \hat{\infty} \infty$ 


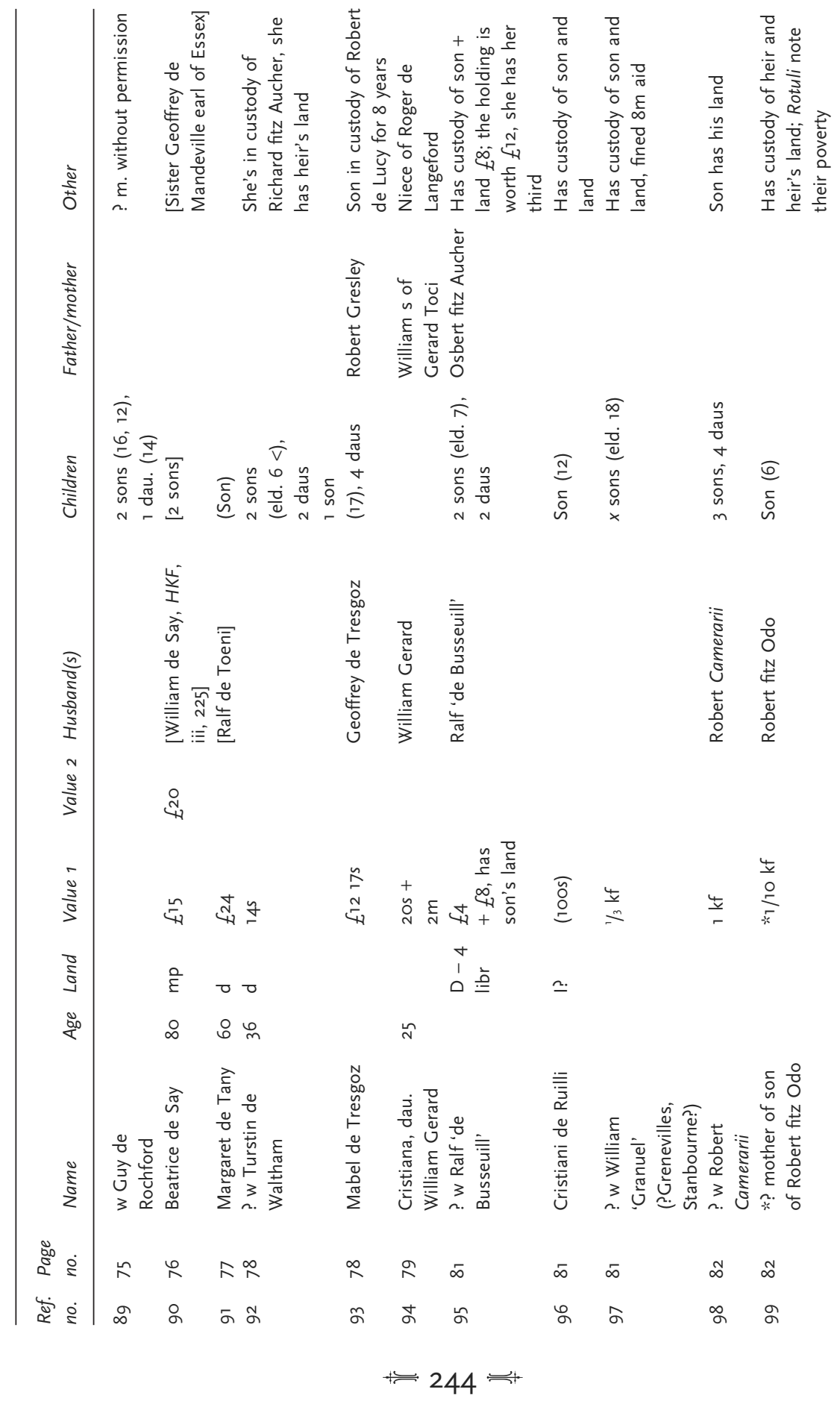



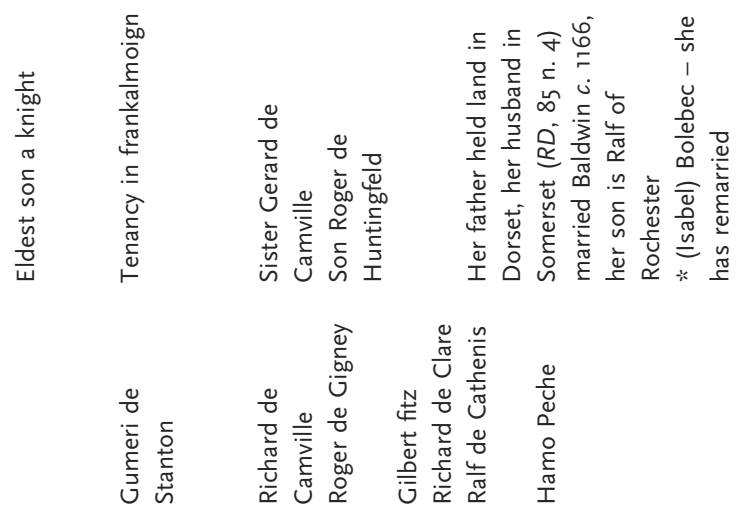

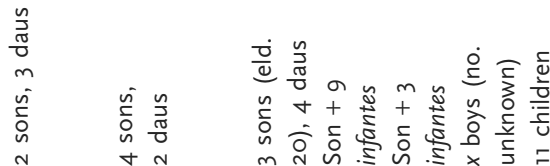

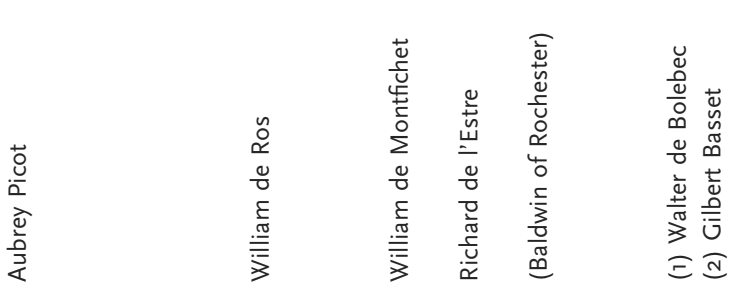

葛

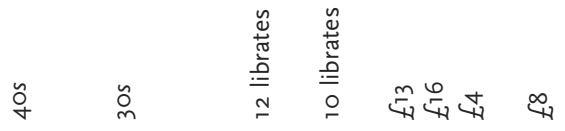

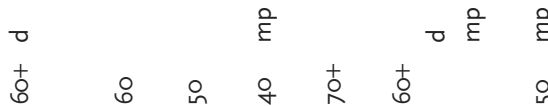

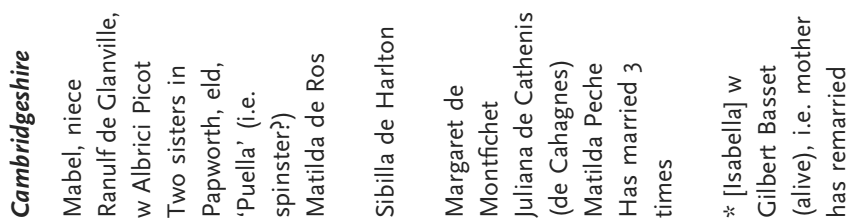

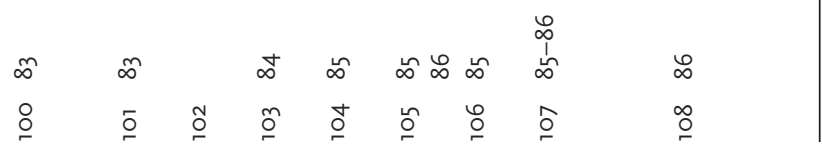


Susan M. Johns - 9781526137555

Downloaded from manchesterhive.com at 04/26/2023 03:11:59PM 